\title{
O Ensino de Física à luz dos livros didáticos (Da Reforma Capanema à Lei 5692/1971)
}

\author{
Teaching Physics according to textbooks \\ (From Capanema Reform to Law 5692/1971)
}

\author{
Yassuko Hosoume*1@, Maria Inês Martins요 \\ ${ }^{1}$ Universidade de São Paulo, Instituto de Física, São Paulo, SP, Brasil. \\ ${ }^{2}$ Pontifícia Universidade Católica de Minas Gerais, Belo Horizonte, MG, Brasil.
}

Recebido em 07 de agosto de 2021. Revisado em 03 de novembro de 2021. Aceito em 16 de novembro de 2021.

Foram pesquisadas quatro décadas de livros didáticos de Física, de 1940 a 1980, no âmbito da história dos conteúdos escolares, procurando caracterizar as propostas de ensino de Física no Brasil, identificando o contexto das políticas educacionais e suas relações com as políticas editoriais. O estudo considera os livros, através de seus autores, seus objetivos educacionais implícitos e explícitos, seus conteúdos específicos e suas propostas de desenvolvimento das atividades pedagógicas. A partir da década de 1940, o mercado editorial de livros didáticos e os autores se concentram em São Paulo, sendo professores de escolas públicas nos primeiros períodos (1940-1950) e professores de cursos preparatórios para o vestibular nas décadas seguintes (1960-1970), muitos deles com livros editados por até 3 (três) décadas. Embora tenham ocorrido no período três reformas educacionais, diferenciandose por: valorização do pensamento cientifico teórico (década de 1940); alinhamento dos temas da física com as áreas da ciência física e acrescentando em sua formulação a importância do caráter experimental (década de 1950); formação tecnológica e profissional (décadas de 1960/1970), a proposta de ensino de Física concretizada em livros de mesma autoria mudou muito pouco, visando a sua adequação a cada nova demanda legal. Por outro lado, a chegada do PSSC no Brasil representa um marco para o ensino da Física, levando às reflexões que resultaram em projetos de ensino no início dos anos 1970, todos com sede em São Paulo, refletindo formas distintas no desenvolvimento dos conteúdos, desde uma visão mais cultural, com a Física bastante contextualizada e o caráter experimental bastante explorado, até projetos com conteúdos bastante teóricos e conceituais, semelhante ao desenvolvimento dos conteúdos propostos em universidades de formação de físicos ou professores de física. Podese dizer que a década de 1970 foi um dos períodos mais ricos em termos de proposições em ensino de física, com diferentes visões de física e de ensino.

Palavras-chave: Livro didático, ensino entre 1940 e 1980, legislação educacional.

Four decades of Physics textbooks were researched, from 1940 to 1980, considering the history of school contents. We characterized the proposals for teaching Physics in Brazil, identifying the contexts of educational policies and their relations with editorial policies. The study considers textbooks, through their authors, their implicit and explicit educational objectives, their specific contents, and their proposals for the development of pedagogical activities. From the 1940s onwards, the textbook publishers and authors were concentrated in São Paulo, being public school teachers in the early periods (1940-1950) and teachers of preparatory courses for colleges' entrance exams in the following decades (1960-1970), many of them with textbooks published for up to 3 (three) decades. Although three educational reforms took place in the period, differing by valuing theoretical scientific thinking (the 1940s); alignment of the physics themes with the physical science areas, and adding in its formulation the importance of the experimental character (the 1950s); technological and professional training (1960s/1970s), the proposal for teaching Physics implemented in textbooks by the same authorship changed very little, aiming to adapt it to each new legal demand. On the other hand, the arrival of the PSSC in Brazil represents a milestone for Physics teaching, leading to reflections that resulted in teaching projects in the early 1970s, all created in São Paulo, reflecting different forms of content development, from a more cultural view, with Physics very contextualized and the experimental character extensively explored, to projects with very theoretical and conceptual content, similar to the development of contents proposed in universities training physicists or physics teachers. It can be said that the 1970s was one of the richest periods in physics teaching propositions, with different visions of physics and teaching.

Keywords: Textbook, teaching between 1940 and 1980, educational legislation.

\footnotetext{
* Endereço de correspondência: yhosoume@gmail.com
} 


\section{Introdução}

Pesquisas sobre manuais escolares que tomam o livro didático como objeto de análise, podem ser identificadas em três principais escopos de interesse. Muitas investigações se voltam para os grandes projetos de ensino de Física descrevendo sua elaboração, analisando sua estrutura interna de conteúdos, avaliando seu uso por professores e alunos ou utilizando sua proposta educacional como referência na análise de outros materiais didáticos. Outros trabalhos tratam os livros didáticos convencionais, identificando os enfoques de suas propostas educacionais, examinando as linguagens discursivas ou gráficas, indicando a correção de conceitos físicos e verificando o caráter dos exercícios teóricos e experimentais. Há, ainda, uma corrente de interesse significativa que contrapõe alternativas de ensino ao uso do livro didático convencional como testemunho do ensino vivenciado em sala de aula, consubstanciandose numa referência curricular real, na perspectiva de Goodson 1 .

As pesquisas na abordagem histórica dos conteúdos, de modo geral, podem ser classificadas em duas perspectivas: aquelas que consideram o livro didático como objeto físico, focalizando, por exemplo, a sua produção, consumo e veiculação e aquelas que consideram o livro didático como documento histórico, analisando os conteúdos em busca de informações significativas [2]. Esta última reflete as pesquisas que "buscam compreender a complexidade do livro didático no ensino de Física, não apenas como mediador da prática pedagógica, mas também como representante do conhecimento de um momento da história" [3]. Segundo Choppin [2], os trabalhos na perspectiva histórica dos conteúdos ganham ênfase a partir de 1970 nos países ocidentais, entretanto no Brasil ainda se encontram restritas, não atingindo uma publicação por ano [4, 5]. Entre essas publicações, destacamos o trabalho de Nicioli Junior [6] que analisa os conteúdos da Cinemática nos livros didáticos de 1810 até 1930, o trabalho de Tavares [7] que relaciona as mudanças na indústria gráfica e imagens em livros didáticos entre os séculos XIX e XX e de Martins [8, que investiga o ensino de física moderna nos livros didáticos do início do século XX.

É, sobretudo no âmbito da história dos conteúdos escolares, que se insere a nossa pesquisa, na qual procuramos caracterizar as propostas de ensino de Física no Brasil durante aproximadamente 40 anos, de 1940 a 1980, identificando, através dos livros didáticos, os contextos das políticas educacionais e suas relações com as políticas editoriais. Centrados nos livros didáticos utilizados no Brasil buscamos melhor compreender o ensino de Física no país, em cada década analisada. O estudo considera os textos escolares, através de seus autores, seus objetivos educacionais implícitos e explícitos, seus conteúdos específicos indicados e suas propostas de desenvolvimento das atividades pedagógicas.

\section{Os Períodos da Pesquisa}

A nossa análise de livros didáticos de Física aborda o período entre os anos em que foram decretadas as Leis Orgânicas do Ensino (1942 a 1946), denominadas como "Reforma Capanema", passando pelos anos que sucederam a publicação da LDB de 1961 [9], até os anos subsequentes à promulgação da Lei n ${ }^{\circ} 5692$ de 1971 [10].

A Lei Orgânica do Ensino Secundário, Lei n ${ }^{\circ} 4244$ de 1942 [11, englobando o ginasial (4 anos) e o colegial (3 anos em duas opções: clássico e científico), disciplinava a formação das elites condutoras. Essa legislação possibilitou a extinção do Curso Secundário Superior, denominado "Preparatório", de caráter complementar, não obrigatório, transformando o Colegial em etapa obrigatória para o acesso ao ensino superior. As demais leis orgânicas destinaram-se a criar e ordenar o ensino profissionalizante nas modalidades industrial, comercial, agrícola e normal que não eram consideradas equivalentes ao colegial [12.

A Lei Orgânica do Ensino Secundário materializou-se através de portarias ministeriais publicadas em 1943 [13] e, novamente em 1951 [14, estabelecendo a distribuição de carga horária e os programas das várias matérias que compõem o nível colegial, diferenciados para os cursos clássico e científico. As aulas de Física no colegial totalizavam cerca de 5 para o clássico (3 aulas na $2^{\text {a }}$ série e 2 aulas na $3^{\mathrm{a}}$ série) e 9 para o científico (3 aulas para cada uma das séries). Os Programas de Física que constam dessas portarias foram elaborados pela Congregação do Colégio Pedro II [15].

A obrigatoriedade de adoção dos programas oficiais foi revogada, com a promulgação da Lei $n^{\circ} 4024$, de 1961, que liberou a escolha dos conteúdos pelas escolas. Esse fato permitiu ao Instituto Brasileiro de Educação, Ciência e Cultura, IBECC, traduzir Projetos de Ensino como PSSC que incluíam, além do texto, filmes, kits de laboratórios e manual para o professor. Como a implantação do Projeto americano em nosso país não foi efetiva, vários projetos como o Projeto de Ensino de Física $(\mathrm{PEF})^{1}$ e o Projeto Brasileiro de Ensino de Física $(\mathrm{PBEF})^{2}$ surgiram no início da década de 1970 com o apoio governamental através do Programa de Expansão e Melhoria do Ensino (PREMEN) [16].

A LDB de 1961 concebia o ensino médio ministrado em dois ciclos, o ginasial (quatro anos) e o colegial (três anos, no mínimo), divididos horizontalmente nos ramos secundário, normal e técnico, possibilitando a equivalência entre os vários ramos de ensino médio profissional e propedêutico. Para cada ciclo havia disciplinas e práticas educativas, obrigatórias e optativas,

\footnotetext{
1 PEF: Projeto de Ensino de Física. Projeto do Instituto de Física da USP. Início: 1971. Cood. Ernst W. Hamburger e Giorgio Moscati. Brasília: MEC/FAI/PREMEN, 1973.

2 PBEF. Projeto Brasileiro de Ensino de Física. Coord. José Goldenberg e Antônio Teixeira Jr. Projeto da FUNBEC. São Paulo: FUNBEC, 1973.
} 
promovendo uma descentralização do ensino através de seu artigo 35:

\section{Ao Conselho Federal de Educação compete indicar, para todos os sistemas de ensino médio, até cinco disciplinas obrigatórias, ca- bendo aos conselhos estaduais de educação completar o seu número e relacionar as de caráter optativo que podem ser adotadas pelos estabelecimentos de ensino [9].}

Entre as disciplinas obrigatórias figuravam as ciências, sendo que Krasilchick [17] afirma que essa legislação ampliou a participação das ciências no currículo escolar, através da disciplina Iniciação Científica figurando desde o $1^{\circ}$ ano do ciclo ginasial. Observa-se, entretanto que a carga horária de Física, Química e Biologia no ciclo colegial diminui pela junção das mesmas na disciplina Ciências Físicas e Biológicas [18.

Quase dez anos depois da LDB de 1961, foi promulgada a Lei $\mathrm{n}^{\circ} 5692$, de 1971, formalizando o $1^{\circ}$ grau com oito anos de duração e o segundo grau com três anos. Essa legislação enfatiza a formação especial com ênfase na habilitação profissional (compulsória), sendo que o Conselho Federal de Educação foi encarregado de fixar "além do núcleo comum, o mínimo a ser exigido em cada habilitação profissional ou conjunto de habilitações afins" (Lei $\mathrm{n}^{\circ} 5692 / 1971$, art. $4^{\circ}$ ), o que foi explicitado no Parecer $n^{\circ} 853 / 1971^{3}$

A redução de um ano de escolaridade, bem como a necessidade de tratar a habilitação profissional provocou mais uma redução na carga horária de várias matérias, inclusive na Física 4 , dificultando o alcance almejado para as Ciências nesta legislação, a saber: o "desenvolvimento do pensamento lógico e a vivência do método científico", sem deixar de por em relevo as tecnologias que resultam de "suas aplicações".

$\mathrm{Na}$ visão de Krasilchick [17], apesar de a legislação induzir o caráter profissionalizante das disciplinas científicas, as escolas privadas continuaram a preparar os alunos para o curso superior e o sistema público também se reajustou sem implantar as pretensões irrealistas de formação profissional por meio de disciplinas pretensamente preparatórias ao trabalho.

Utilizando essas delimitações históricas da educação brasileira, o nosso primeiro período de análise reporta à década de 1940, em que prevalece o programa disciplinar proposto pela Reforma Capanema. No segundo período

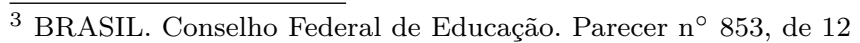
nov. 1971. Núcleo-comum para os currículos do ensino de $1^{\circ}$ e $2^{\circ}$ graus. A doutrina do currículo na Lei 5.692

4 O Parecer $n^{\circ} 853 / 1971$ estabelece que "no ensino de $2^{\circ}$ grau, sob as formas de Língua Portuguesa e Literatura Brasileira, História, Geografia, Matemática e Ciências Físicas e Biológicas, tratadas predominantemente como disciplinas e dosadas segundo as habilitações profissionais pretendidas pelos alunos." Ou seja, no $2^{\circ}$ grau são possíveis "variações não somente de carga horária como do número de períodos letivos em que seja incluída cada disciplina e, eventualmente, área de estudo ou atividade".
}

da análise encontram-se os livros didáticos das décadas de 1950, elaborados com base no programa estabelecido pela Portaria ${ }^{\circ} 996$ de 1951 e especificadas pela Portaria $\mathrm{n}^{\circ} 1045$, do mesmo ano. O último período de análise corresponde às décadas de 1960 e 1970, em que não existem programas obrigatórios definidos pelo MEC 5 Com a Lei de 1971 foram definidas as diretrizes e bases para o ensino de $1^{\circ}$ e $2^{\circ}$ graus, produzindo em conjunto com a legislação referente aos demais níveis de ensino, uma mudança radical na educação brasileira.

\section{Os Primeiros Livros de Física do Curso Colegial}

Como fontes de pesquisa, utilizamos primordialmente o Banco de Dados Livres ${ }^{6}$ a a lado dos acervos das bibliotecas Nacional/RJ, Poli/USP; IF/USP e PUC/Minas, além de nossos acervos particulares, constituindo-se em um total de cerca de 250 livros de Física e mais de meia centena de autores.

Muitos livros, principalmente os mais antigos, não informam o número da edição, e foi bastante raro encontrar textos em sua primeira edição. Em função disso, a indicação do número da edição é apresentada apenas nas obras em que esse dado é especificado, significando que várias obras podem ter sido editadas anteriormente à data indicada adiante no Quadro 1 .

Do período em que prevaleceu o Programa estabelecido pela Portaria $\mathrm{n}^{\circ} 170$ de 1942 , identificamos os livros ou coleções e os respectivos autores apresentados no Quadro 1] É possível observar nesse quadro que ao ser estabelecido, em 1942, o nível colegial, como etapa obrigatória para o ingresso no ensino superior, já existia cerca de uma dezena de livros de autores brasileiros. Ainda que constem do quadro apenas autores brasileiros, textos estrangeiros, como o de J. Kleiber [19] já se encontravam na $6^{\text {a }}$ edição em 1953. No acervo também foi encontrado um livro de 1933 deste mesmo autor.

Embora nosso interesse se localize a partir da década de 1940, optamos por mencionar algumas características dos livros didáticos, sobretudo na década anterior, quando várias publicações já se encontravam consolidadas no mercado específico do texto escolar. Como

\footnotetext{
5 A doutrina da Lei $\mathrm{n}^{\circ} 5692 / 1971$, estabelecida através do Parecer $\mathrm{n}^{\circ} 853 / 1971$, em relação ao Núcleo-comum para os currículos de ensino de $1^{\circ}$ e $2^{\circ}$ graus, delibera aos estados a construção de guias curriculares. O Estado de São Paulo publica seus guias no ano de 1975 .

6 O Banco de Dados LIVRES disponibiliza pela Internet o acesso à produção das diversas disciplinas escolares brasileiras desde o século XIX até os dias atuais, fornecendo também referenciais e fontes, por intermédio da recuperação de obras e coleta de documentos sobre a produção didática, legislação, programas curriculares, catálogos de editoras, etc. A organização do Banco de Dados LIVRES se insere no projeto temático "Educação e Memória: organização de acervos de livros didáticos", financiado pela Fundação de Amparo à Pesquisa do Estado de São Paulo (FAPESP), no Centro de Memória da Educação Escolar, da Faculdade de Educação da Universidade de São Paulo (CME).
} 
Quadro 1: Livros didáticos de Física do período: 1940-1979.

\begin{tabular}{|c|c|c|c|c|c|c|}
\hline \multirow[b]{2}{*}{ Cidade } & \multirow[b]{2}{*}{ Editora } & \multirow[b]{2}{*}{ Autor(es) } & \multicolumn{4}{|c|}{ Ano } \\
\hline & & & 1940 à 1950 & 1951 à 1960 & 1961 à 1970 & 1971 à 1979 \\
\hline \multirow[t]{10}{*}{ Rio de Janeiro } & \multirow[t]{3}{*}{$\begin{array}{l}\text { Francisco } \\
\text { Alves }\end{array}$} & $\begin{array}{l}\text { Lamare, João } \\
\text { Gomes }\end{array}$ & 1944 & & & \\
\hline & & $\begin{array}{l}\text { Marciano, Irmão } \\
\text { Mário }\end{array}$ & 1946 & 1953 & & \\
\hline & & Lucie, Pierre & & & & 1977 \\
\hline & \multirow[t]{2}{*}{ Livro Técnico } & $\begin{array}{l}\text { Pinto, Herbert \& } \\
\text { Pinto, Dilson }\end{array}$ & & 1957 & & \\
\hline & & Gonçalves, Dalton & & 1960 & $\begin{array}{l}1962 / 64 / 65 / \\
66 / 67 / 68 / 70\end{array}$ & $72 / 74$ \\
\hline & \multirow[t]{2}{*}{$\begin{array}{l}\text { INEP Fundo } \\
\text { de Cultura } \\
\text { FENAME }\end{array}$} & $\begin{array}{l}\text { Blackwood, O.H. } \\
\text { at al (trad.) }\end{array}$ & & & $1962 / 68$ & \\
\hline & & Maia, L.P.M. & & & 1969 & 1979 \\
\hline & EDIL & $\begin{array}{l}\text { Freire, Délio \& } \\
\text { Muniz, Paulo P. }\end{array}$ & & & 1969 & \\
\hline & Nacionalista & Maia, L.P. & & 1960 & 1964 & \\
\hline & $\begin{array}{l}\text { Raval Artes } \\
\text { Gráficas }\end{array}$ & Lucie, Pierre & & & 1969 & \\
\hline \multirow[t]{4}{*}{ Porto Alegre } & \multirow[t]{3}{*}{ Globo } & $\begin{array}{l}\text { Lemoine, J. \& } \\
\text { Guyot (tradução) }\end{array}$ & & 1959 & & \\
\hline & & $\begin{array}{l}\text { Kleiber, J. } \\
\text { (tradução) }\end{array}$ & & 1953 & & $1976(?)$ \\
\hline & & $\begin{array}{l}\text { Maiztegui, } \\
\text { A.P.(tradução) }\end{array}$ & & & & 1972 \\
\hline & Sagra & $\begin{array}{l}\text { Chemello, A. \& } \\
\text { Luzzatto, D.C. }\end{array}$ & & 1955 & & \\
\hline Belo Horizonte & $\begin{array}{l}\text { Bernardo } \\
\text { Àlvares }\end{array}$ & $\begin{array}{l}\text { Alvarenga, B. \& } \\
\text { Máximo A. }\end{array}$ & & & 1970 & $1971 / 74$ \\
\hline \multirow{24}{*}{ São Paulo } & \multirow{5}{*}{ Nacional } & Gomes Filho, F.A. & $1944 / 1950$ & $1953 / 55 / 57 / 59$ & $1961 / 65$ & \\
\hline & & Schenberg, Mário & 1945 & & & \\
\hline & & Zanello, H. & 1945 & & & \\
\hline & & Ferreira, L.C. & & & & $1974 / 75$ \\
\hline & & Santos, U.P. & & & 1967 & \\
\hline & \multirow{2}{*}{$\begin{array}{l}\text { Melhora- } \\
\text { mentos }\end{array}$} & Freitas, A. & $1946 / 47 / 48 / 49$ & $1951 / 53 / 60$ & & \\
\hline & & $\begin{array}{l}\text { Silva, Valter } \\
\text { Toledo }\end{array}$ & 1944 & & & \\
\hline & \multirow[t]{5}{*}{ Livraria Nobel } & Rozenberg, I.M. & & & 1961 & \\
\hline & & Senberg, G. & & & $1962 / 65$ & \\
\hline & & Heilmann, H. Peter & & & 1976 & \\
\hline & & $\begin{array}{l}\text { Nora Antunes, } \\
\text { A.A. \& Fragoso, L. }\end{array}$ & & & $1967 / 69 / 70$ & $72 / 74$ \\
\hline & & Johnson, T.N.O.F. & & 1958 & $196 ?$ & \\
\hline & \multirow[t]{3}{*}{$\begin{array}{l}\text { Editora do } \\
\text { Brasil }\end{array}$} & $\begin{array}{l}\text { Nabholz, Hermann } \\
\text { Urbano }\end{array}$ & 1947 & & & \\
\hline & & $\begin{array}{l}\text { Teixeira Jr, A. S. } \\
\text { \& Rizzo, Mário. }\end{array}$ & & 1958 & $1964 / 66$ & \\
\hline & & Teixeira Jr, A.S. & & & $1962 / 64 / 66$ & \\
\hline & $\begin{array}{l}\text { Clássico - } \\
\text { Científico }\end{array}$ & $\begin{array}{l}\text { Rodrigues, C.E. \& } \\
\text { Pieroni, R.R. }\end{array}$ & $194 ?$ & 1957 & $196 ?$ & \\
\hline & Saraiva e Cia & Pereira, Urbano & 1944 & & & \\
\hline & Massa Ohno & Gabriades, E & & 1960 & & \\
\hline & \multirow[t]{4}{*}{ Moderna } & Maia, L.P.M. & & & 1964 & \\
\hline & & $\begin{array}{l}\text { Antunes, A.A.N. \& } \\
\text { Fragoso, L. }\end{array}$ & & & 1969 & \\
\hline & & Omote, N. & & & & $1976 / 79$ \\
\hline & & $\begin{array}{l}\text { Ueno, P.T.; } \\
\text { Yamamoto, I. }\end{array}$ & & & & 1977 \\
\hline & \multirow[t]{2}{*}{ FTD } & Maristas & & & 1965 & \\
\hline & & FTD & & & $196 ?$ & \\
\hline
\end{tabular}

(Continued) 
Quadro 1: Continued

\begin{tabular}{|c|c|c|c|c|c|c|}
\hline \multirow[b]{2}{*}{ Cidade } & \multirow[b]{2}{*}{ Editora } & \multirow[b]{2}{*}{ Autor(es) } & \multicolumn{4}{|c|}{ Ano } \\
\hline & & & 1940 à 1950 & 1951 à 1960 & 1961 à 1970 & 1971 à 1979 \\
\hline & LPM & $\begin{array}{l}\text { Figueiredo, E.\& } \\
\text { Carvalho, F.R. }\end{array}$ & & & 1965 & \\
\hline & Atual & $\begin{array}{l}\text { Ferraro, N.G.; } \\
\text { Soares, P.A.T.; } \\
\text { Santos, J.I.C. }\end{array}$ & & & & 1979 \\
\hline & & $\begin{array}{l}\text { Santos, U.P. ; } \\
\text { Riguetto, L. }\end{array}$ & & & & 1977 \\
\hline & Ática & $\begin{array}{l}\text { Lenz, U. ; Moretto, } \\
\text { V.P. }\end{array}$ & & & & 1979 \\
\hline & $\begin{array}{l}\text { Sem } \\
\text { identificação }\end{array}$ & Salmeron, R. & & $1953 / 58$ & 1962 & \\
\hline Sem identificação & $\begin{array}{l}\text { Sem } \\
\text { identificação }\end{array}$ & Lopes Neto, F. & & 1954 & & \\
\hline
\end{tabular}

Fonte: Dados da Pesquisa

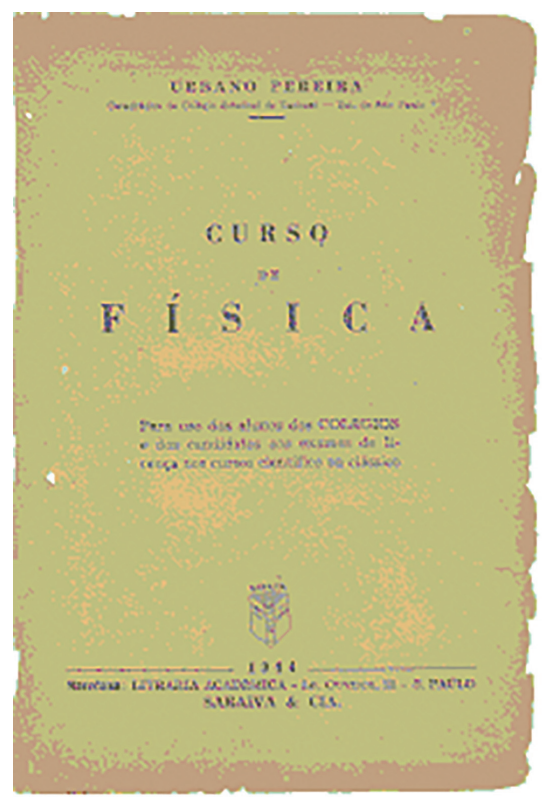

Figura 1: Capa de livro de Urbano Pereira. Fonte: Pereira [23.

exemplos, apresentamos Lourenço [20] e Nobre [21], respectivamente, em suas $6^{\mathrm{a}}$ e $23^{\mathrm{a}}$ edições. Esses livros funcionavam como títulos de referência, como "tratados" ou "compêndios" de Física, apresentados em volume único, chegando a atingir várias centenas de páginas 7

$\mathrm{Na}$ década de 1940, poucos títulos se mantêm na forma de volume único 23] (Figura 1) cedendo lugar às publicações focalizadas em séries específicas, com destinação explicitada em subtítulo como em Gomes Filho [24] "Física para a Terceira Série do Curso Colegial" (Figura 2) ou Marciano [25] "Física: ciclo colegial:

\footnotetext{
7 Essas características podem ser observadas nas obras: "Tratado de Física Elementar" 21, "Tratado de Física Experimental" 20. Entre os livros mais grossos da época, destacamos Magalhães 22 e Kleiber 19], esse último traduzido pelo próprio Magalhães, com 388 e 614 páginas, respectivamente.
}

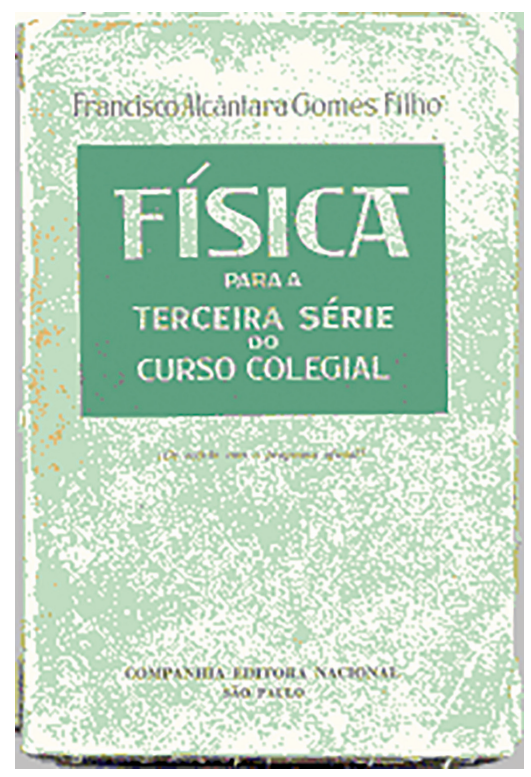

Figura 2: Capa de livro de Francisco A. Gomes Filho. Fonte: Gomes Filho [24].

segunda série do curso científico". Freitas [26] (Figura 3] por outro lado, indica no prefácio a adequação de seu livro para a $1^{\mathrm{a}}$ e $2^{\mathrm{a}}$ séries do curso científico. Nessa época as editoras localizavam-se, preferencialmente, nas cidades de São Paulo/SP e Rio de Janeiro/RJ, sendo a primeira delas responsável por ao menos $70 \%$ dos títulos mais significativos de Física.

Acerca da formação e atuação dos autores, observamos que, na década de 1940, até meados de 1950, grande parte atuava em colégios tradicionais do Ensino Secundário. Anibal Freitas lecionava no Ginásio Oficial de Campinas/SP; Francisco Alcântara Gomes Filho atuava no Colégio Pedro II/RJ, Urbano Pereira no Colégio Estadual de Taubaté/SP e Irmão Mario Marciano atuava no Colégio Marista de Santos/SP. Os livros didáticos, nesta ocasião, representavam a consolidação de suas experiências didáticas e pareciam fazer 


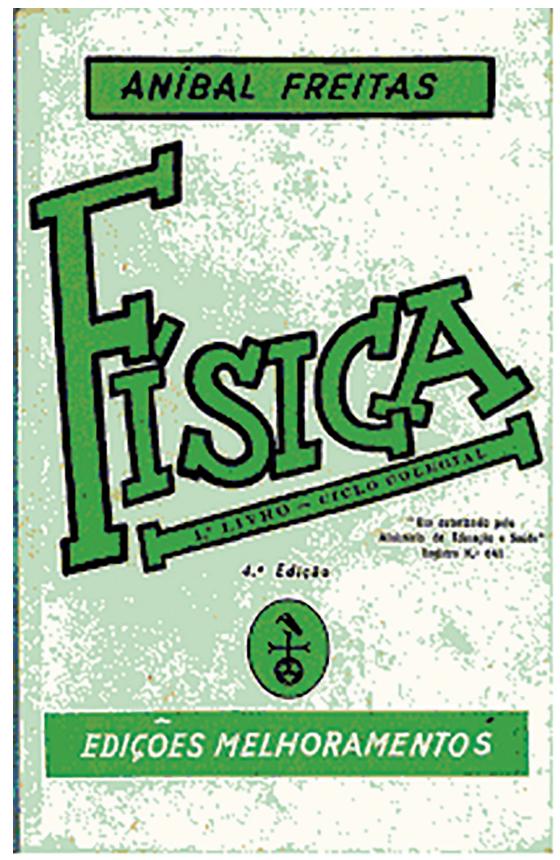

Figura 3: Capa de livro de Anibal Freitas. Fonte: Freitas [26].

sucesso entre professores e alunos, pois chegaram a ser produzidos muitos exemplares em várias edições. Citamos o exemplar n ${ }^{\circ} 3885$, da $8^{\text {a }}$ edição da publicação de Francisco Alcântara Gomes Filho [27, bem como a tiragem de 44000 exemplares da $8^{\mathrm{a}}$ edição da obra de Anibal Freitas [28. Destacamos, ainda, a edição de seus livros didáticos durante ao menos duas décadas (Freitas: décadas de 1930 a 1950 e Gomes Filho: décadas de 1940 a 1960). Ao lado desses nomes, autores como Rodrigues Celestino \& Pieroni 29] perduraram, por mais de 20 anos, entre as décadas de 1940 e 1960.

Todas as coleções apresentam nas páginas iniciais o programa de Física estabelecido pela Portaria $n^{\circ}$ 170/1943, sendo que a maioria delas informa o programa do científico, com exceção de Pereira 23] que apresenta ambos os programas, científico e clássico. A diferença entre os dois programas aparece na profundidade da abordagem, pois os temas são praticamente idênticos, distribuídos tanto nas três séries do científico quanto nas duas séries do clássico. Por exemplo, na terceira série do científico o tópico introdutório "A medida Física" é, de fato, um aprofundamento da temática abordada na introdução ao curso, na $1^{\text {a }}$ série, que discute lei Física, medida, erro, precisão, medidas de grandezas geométricas. Tal retomada de conteúdo na $3^{\mathrm{a}}$ série considera itens, tais como: sistemas de unidades coerentes, fórmulas dimensionais, homogeneidade das equações da Física e noções de cálculos de erros.

Numa época de valorização do pensamento científico, a Física se expressa, através do "método Experimental" (Figura 4), ainda que esse enfoque tenha como elemento principal a unidade introdutória. No livro de
Outrossim, procurando habituar os alunos com - método da Física Experimental, incluimos ainda na Introdução, algumas noções sôbre construção e interpretação de diagramas, uteis a vários pontos do programa.

\section{Gomes Filho, 1944. PREFÁCIO}

Figura 4: Trecho de livro de Gomes Filho. Fonte: Gomes Filho [31 prefácio].

Freitas 30, conteúdos relativos a lei e medida física ocupam $8 \%$ do total, enquanto que nas obras de Gomes Filho 24 e de Pereira 23] chegam a preencher $20 \%$ do conteúdo, atestando a importância dada ao tema por estes autores. Apesar desse enfoque, apenas o livro de Pereira 23 propõe atividades experimentais, indicando que o método da Física Experimental parece ser compreendido como a resolução numérica de problemas teóricos.

Os temas propostos para serem abordados em cada série do científico são: $1^{\mathrm{a}}$ Série: Introdução; A Estática

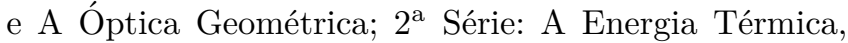
A Energia Elétrica e A Energia Cinética; $3^{\mathrm{a}}$ Série: A Medida Física, A Física Ondulatória, Os campos de Força, A Física Corpuscular. Destacamos que:

- na $1^{\mathrm{a}}$ série os conteúdos têm uma abordagem "estática", ou seja, são tratados temas nos quais as análises são espaciais e atemporais. Essa proposta parece indicar que a visão espacial é explorada antes da visão temporal (estática $=$ equilíbrio e óptica geométrica $=$ raios de luz). Entretanto, ao analisarmos os conteúdos integrantes da estática e da óptica geométrica, observamos grande semelhança com aqueles desenvolvidos nos livros didáticos atuais.

- na $2^{a}$ série a estruturação é proposta através do tema "energia", iniciando com a energia térmica, que é a forma de energia que permite uma discussão mais abrangente da conservação da energia, diferindo consideravelmente dos livros atuais. Ainda que essa perspectiva nos pareça mais consistente do ponto de vista da compreensão da energia, ao olharmos para os conteúdos integrantes destes temas, verificamos que são praticamente os mesmos dos livros atuais (energia térmica bastante semelhante Termologia + termodinâmica; energia elétrica equivalente à atual eletrodinâmica e energia cinética similar ao tratamento atual na $\mathrm{Ci}$ nemática e Dinâmica). Outro aspecto interessante é o estudo da rotação, com a utilização do conceito de momento de inércia e energia de rotação.

- na $3^{\mathrm{a}}$ série a estruturação da terceira unidade é feita através de campos de força. São apresentados os três campos (gravitacional, elétrico e magnético), seguidos pelo eletromagnetismo de 
modo símile aos índices dos livros didáticos atuais. Em Física corpuscular são tratados raios catódicos, raios $\mathrm{X}$ e partículas elementares.

Os títulos das unidades, em todos os livros analisados, seguem aqueles estabelecidos pelo programa oficial. Quanto ao desenvolvimento dos conteúdos, os livros de Aníbal Freitas são os mais "sintéticos" normalmente o autor define ou apresenta conceitos, leis, ou demonstrações de forma bem simplificada, sem discussões conceituais. Comparando o número de páginas dos conteúdos relativos ao $1^{\circ}$ ano do científico, em Freitas 30 constam 250 páginas, em Gomes Filho 31 321 páginas e em Nabholz [32 318 páginas. Apesar de todos os manuais terem sido editados em branco e preto, no livro de Freitas [33], adequado ao $3^{\circ}$ ano, encontramos fotos coloridas dos espectros da luz solar, de emissão do arco elétrico e de vapores de sódio, de hidrogênio e alguns elementos químicos. Uma característica dos textos desse período é a indicação dos conteúdos como leis, experimentos, relações e propriedades por números que no decorrer do texto são retomadas através dessas identificações (Figura 5).

Os exercícios nos livros de Freitas e Gomes Filho se resumem às aplicações numéricas das equações apresentadas teoricamente, da ordem de dois a três exercícios resolvidos após a apresentação teórica (Figura 6). O livro de Rodrigues e Pieroni [34, dirigido ao $2^{\circ}$ ano apresenta 231 exercícios propostos, entre cinco e dez ao final de cada capítulo. Rodrigues é ainda coautor de "900 exercícios de Física" 35.

94. Método do frasco ou do picnômeto. sólidos. Emprega-se êste método picnômetro. - 1) Corpos. rência a densidade dos corpos pulverulento determinar de preferencia a densidade dos corpos pulverulentos. 0 aparelho usado é um frasco leve de vidro (picnômetro), com uma rồlha ôca

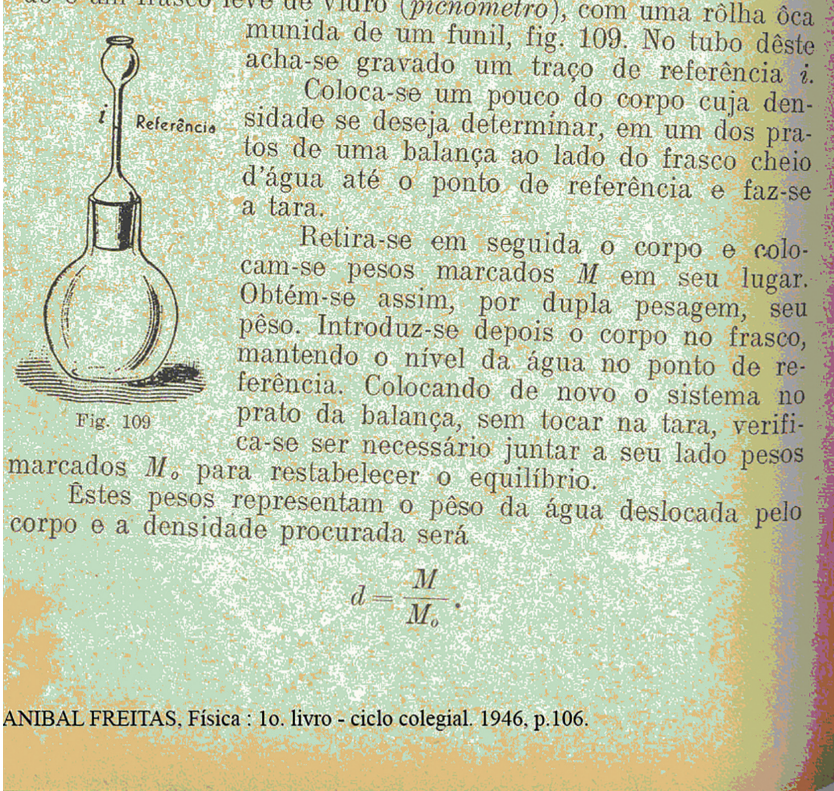

Figura 5: Trecho de livro de Anibal Freitas. Fonte: Freitas [30, p. 106].

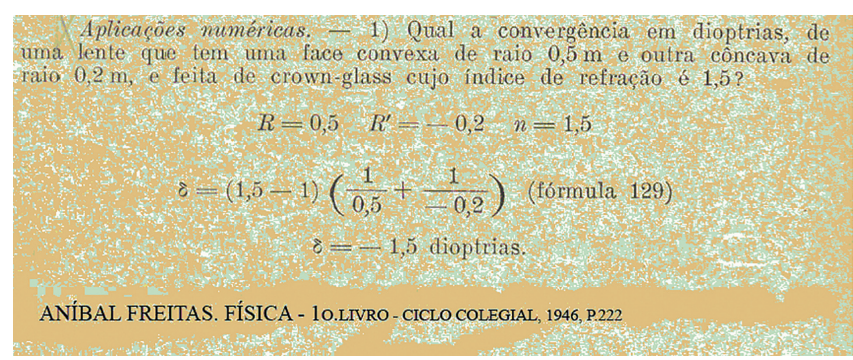

Figura 6: Trecho de livro de Aníbal Freitas. Fonte: Freitas [30, p. 222].

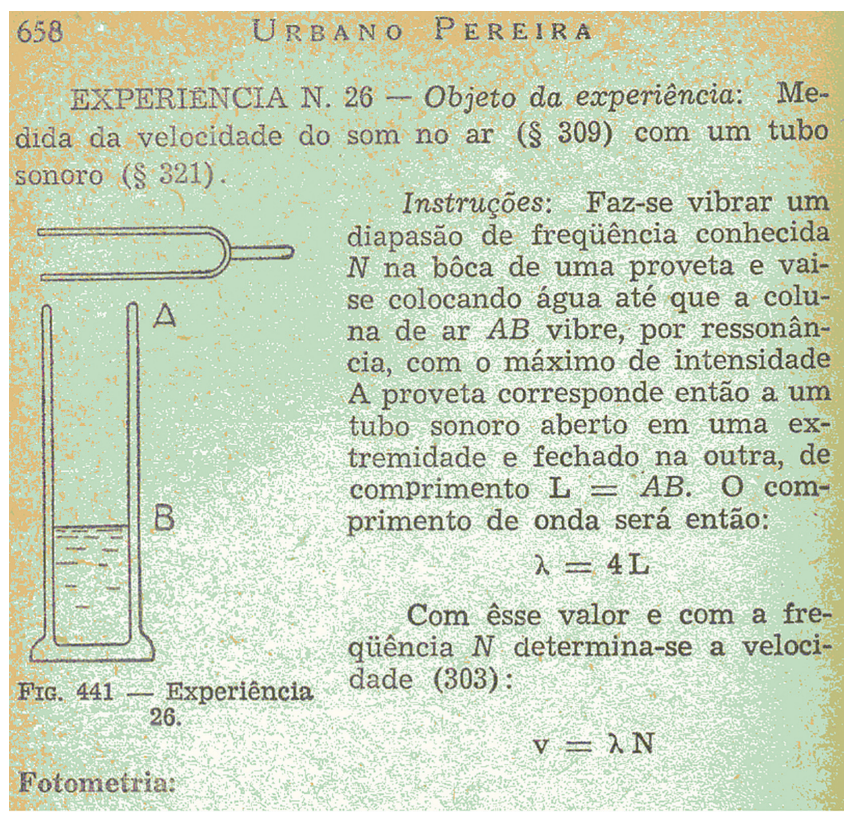

Figura 7: Trecho de livro de Urbano Pereira.

Fonte: Pereira [23, p. 658].

O livro de Pereira 23, em volume único de 671 páginas é interessante, em vários aspectos. Os conteúdos do $1^{\circ}$ ano estão em 170 páginas, do $2^{\circ}$ em 180 e do $3^{\circ}$ em 219 páginas, ou seja, aumentando do $1^{\circ}$ para o $3^{\circ}$. E, ainda, é o único título entre aqueles estudados que propõe atividades experimentais para o aluno. Nesse livro, os problemas (150/ano) e trabalhos práticos (15/ano) encontram-se no final do livro. No corpo do texto são indicados os problemas e os trabalhos práticos a serem realizados pelos alunos (Figura 7). Também é o único texto que apresenta problemas conceituais, indicando como resposta a página do livro, em que a teoria pode auxiliar na sua solução.

Todos os autores dessa fase descrevem experimentos ou aparatos experimentais históricos, uns com menos detalhes como Gomes Filho e outros com riqueza de detalhes semelhantes aos livros da década anterior, como aqueles de autoria de Aníbal Freitas.

Também merece destaque o livro de Rodrigues e Pieroni 34 que, embora não proponha práticas de laboratório, desenvolve vários "estudos experimentais", para 


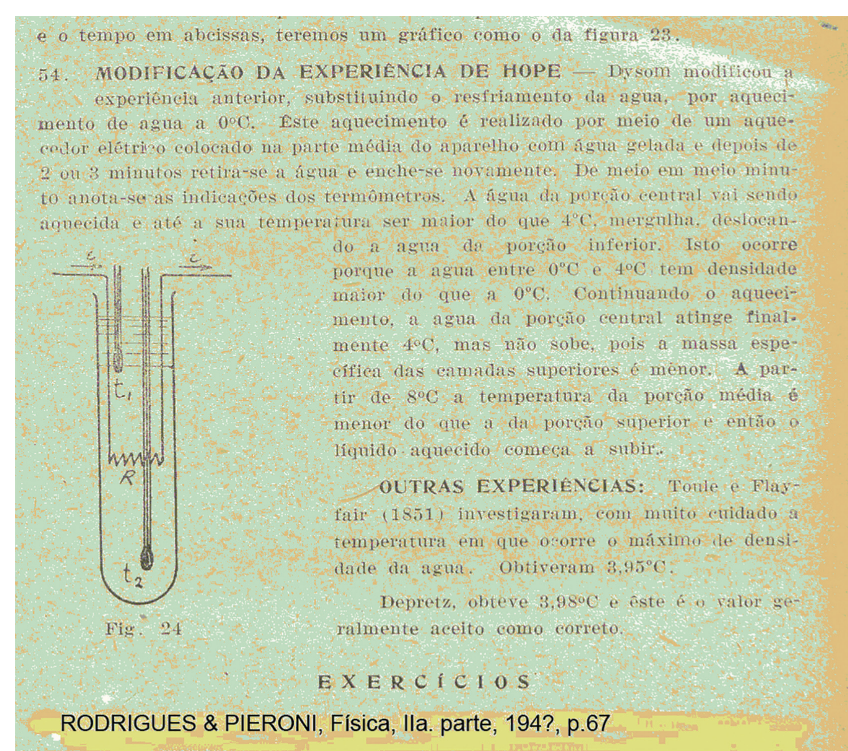

Figura 8: Trecho de livro de Rodrigues \& Pieroni. Fonte: Rodrigues \& Pieroni [34 p. 67].

uma dada equação ou para uma situação de interação. Nestes estudos, os autores descrevem a experiência e atribuem valores experimentais, que acompanhados de uma análise, articulam os resultados com o desenvolvimento teórico do conteúdo. Outro aspecto que diferencia este livro é a apresentação de elementos que, de alguma forma, revelam o processo de construção do conhecimento científico, principalmente no que se refere ao avanço de resultados experimentais. Na Figura 8 exemplificamos este fato através da medida do valor da temperatura em que ocorre a densidade máxima da água. Este livro também inova ao considerar valores numéricos ou situações reais no desenvolvimento do conteúdo. Ao abordar, por exemplo, a eletrodinâmica, o autor insere uma tabela de condutores de cobre utilizados em instalações elétricas, com valores de suas resistências e correntes máximas permissíveis, que, na explanação do motor Diesel e máquinas a vapor, possibilitam o dimensionamento de rede elétrica.

Exemplos dessa natureza são também encontrados no livro de Marciano [25, que apresenta cálculos de aplicações da duração de uma força para a mudança de velocidade de um corpo como frenagem de trens ou recuo de martelo batendo em um prego. Outro aspecto importante do livro de Marciano [25] é o seu caráter interdisciplinar, relacionando, em vários momentos, os conteúdos da Física com aqueles de outras áreas do conhecimento, como a Biologia. Um exemplo de interdisciplinaridade aparece no estudo da propriedade anômala da água durante o congelamento, conferindo-lhe o papel termoregulador da temperatura da atmosfera junto à água do mar, rios e lagos. É possível, também que este tenha sido o único autor do período que trata, embora pontualmente, alguns aspectos da evolução dos conceitos da Física, como por exemplo, ao apresentar historicamente a compreensão do calor (fogo, calórico, hipótese newtoniana das emissões e teoria cinética).

Embora todos os livros analisados da década de 1940 apresentem, como índice os conteúdos disciplinares propostos pela Portaria 170/1942, as diversas formas de desenvolvimento dos conteúdos revelam compreensões distintas da ciência Física. De um modo geral, os livros de Freitas e Gomes Filho apresentam uma Física mais fragmentada, composta de definições, pequenos cálculos numéricos, bem como a visão do caráter experimental da ciência restrito à descrição de experimentos mais técnicos. O livro de Urbano Pereira, embora também revele este aspecto da apresentação de definições, por outro lado, incorpora uma Física um pouco mais conceitual e uma visão mais experimental dessa Ciência revelada através dos experimentos propostos aos alunos. Destacamos ainda que alguns aspectos da Física como elementos de cultura são encontrados nos livros de Rodrigues e Pieroni [34] e Marciano 25].

\section{A Portaria no 996/1951 e os Impactos nos Programas de Física}

Durante 10 anos, de 1951 à LDB de 1961, o ensino de física na escola secundária é norteado pelo programa estabelecido pela Portaria $n^{\circ} 996 / 1951$, que reorganiza os conteúdos de Física. O novo programa perde temas estruturadores como Energia e Campos de forças e, ainda a sequência de conteúdos segue de perto as grandes áreas da física estabelecidas historicamente. Na nova proposta não existem explicitamente títulos que identifiquem as áreas da Física, mas apenas itens sequenciais de conteúdo. Em relação a esse aspecto, propõem-se os seguintes conteúdos para o curso científico: para o $1^{\circ}$ ano são abordados Fenômenos, Leis e Medidas em Física, Estática, Cinemática, Dinâmica. No $2^{\circ}$ ano são propostos os conteúdos relativos ao estudo do som e do calor (Física Ondulatória e Física Térmica). Para o $3^{\circ}$ ano restam os conteúdos relativos à Óptica (geométrica e física), Eletrostática, Magnetismo, Eletromagnetismo, Física Corpuscular e Teorias modernas da Física.

A mesma legislação, segundo Vechia e Lorenz [15], considera também as atividades práticas para as três séries (Figura 9), com a ressalva de que essas atividades são extracurriculares. Ao todo são propostas 24 (vinte e quatro) experimentações, sendo 9 (nove) práticas para a $1^{\mathrm{a}}$ série, 6 (seis) para a $2^{\mathrm{a}}$ série e 9 (nove) para a $3^{\mathrm{a}}$ série.

No programa de 1943, os princípios da dinâmica não são tratados como os fundamentos da área no $1^{\circ}$ ano, como no programa de 1951 , mas sim, no $2^{\circ}$ ano na unidade "A Energia Cinética", dentro da dinâmica dos movimentos de translação juntamente com o teorema das forças vivas. Tanto no programa de 1943, quanto naquele de 1951, esses princípios são precedidos pelo estudo descritivo dos movimentos (cinemática).

A passagem da legislação de 1943 para 1951, inclui a eliminação da unidade "Os Campos de Força", e os 


Todas as vezes que o curso comportar a presença dos alunos no
gabinete de Física em horas extracurriculares, ser-lhes-á facultado o
uso de aparelhos, bem como a execução dos seguintes trabalhos:
PRIMEIRA SÉRIE
a) práticas com o Vernier retilíneo e curvilineo;
b) prática com o paquímetro, palmer, parafuso micrométrico e
esferômetro;
c) medidas de comprimentos e espessuras;
d) medidas de áreas por pesagem;
e) medidas de volumes de sólidos;
f) medidas de ângulos
g) medida da capacidade de um vaso por pesagem;
h) densidade de sólidos e líquidos;
i)práticas com a prensa hidráulica;
j) práticas com o barômetro.
Fonte: Vechia \& Lorenz, 1998, p.404.

Figura 9: Trecho de livro de Vechia \& Lorentz. Fonte: Vechia \& Lorentz [15 p. 404].

conteúdos relativos aos campos elétrico e magnético são distribuídos na $3^{\mathrm{a}}$ série. Os campos de gravitação e de gravidade tratados na última série do programa de 1943 não aparecem como campos no programa de 1951, mas apenas como 'gravidade' nos conteúdos da $1^{\text {a }}$ série dentro do tópico gravitação. Na nova portaria há, ainda, um avanço nos conteúdos para o ensino, pois além da "Física Corpuscular" está previsto o tópico "Teorias Modernas da Física".

Com a Portaria $\mathrm{n}^{\circ} 1.045$ [36], de 1951, o MEC, através das "Instruções metodológicas para o ensino de Física" são discriminados, com detalhes, os conteúdos a serem desenvolvidos em cada série do ciclo colegial. Destacamos, de Freitas [28] um extrato dessa portaria relativo à $1^{\mathrm{a}}$ série. (Figura 10 )

Em relação aos livros didáticos de Física, Aníbal Freitas continua figurando entre os autores até o início da década de 1960, perfazendo aproximadamente 30 anos de publicação. Francisco Gomes Filho e Rodrigues e Pieroni também permanecem até meados da mesma década, publicando livros por mais de 20 anos.

Novos autores aparecem na década de 1950, sobretudo Dalton Gonçalves, Roberto Salmeron e Teixeira Junior \& Rizzo, permanecendo com publicações por mais de 10 anos. O número de títulos neste período aumenta ligeiramente, totalizando cerca de uma dezena. Em relação às editoras, a cidade de São Paulo continua absorvendo aproximadamente $60 \%$ das publicações (Quadro 11).

Nos livros desses cinco autores cujas publicações tiveram uma longa continuidade, todos seguem a sequência dos conteúdos da Portaria $n^{\circ}$ 996/1951, sendo que a enumeração dos capítulos é muito próxima dos itens da Portaria $\mathrm{n}^{\circ} 1045$ do mesmo ano. O desenvolvimento dos conteúdos para alguns autores como Aníbal Freitas e Gomes Filho quase não mudam com a última Portaria, ocorrendo apenas deslocamentos de itens, visando a adequação à sequência de conteúdos da nova legislação. Esta adequação ocorre tanto dentro de uma mesma série, quanto de uma série para a outra, fato este, explicitado,

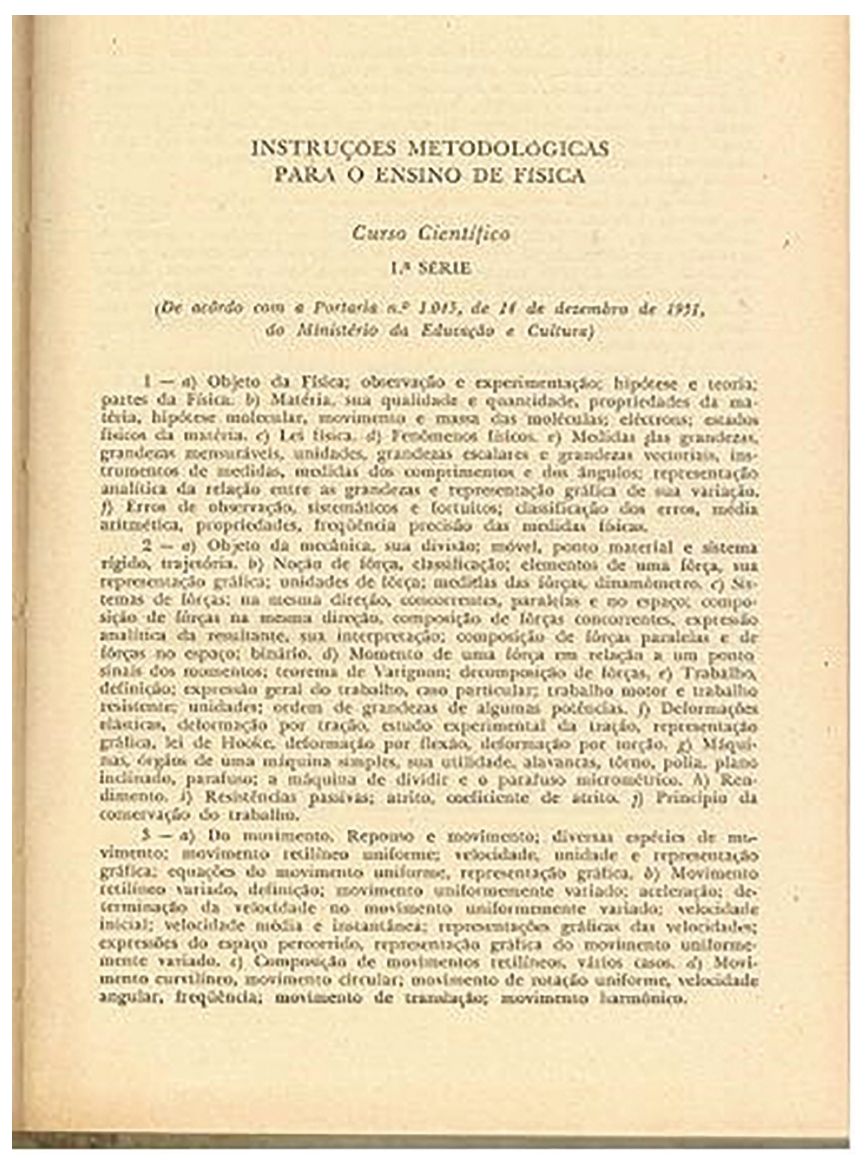

Figura 10: Trecho de livro de Anibal Freitas Fonte: Freitas [28, p. 5]

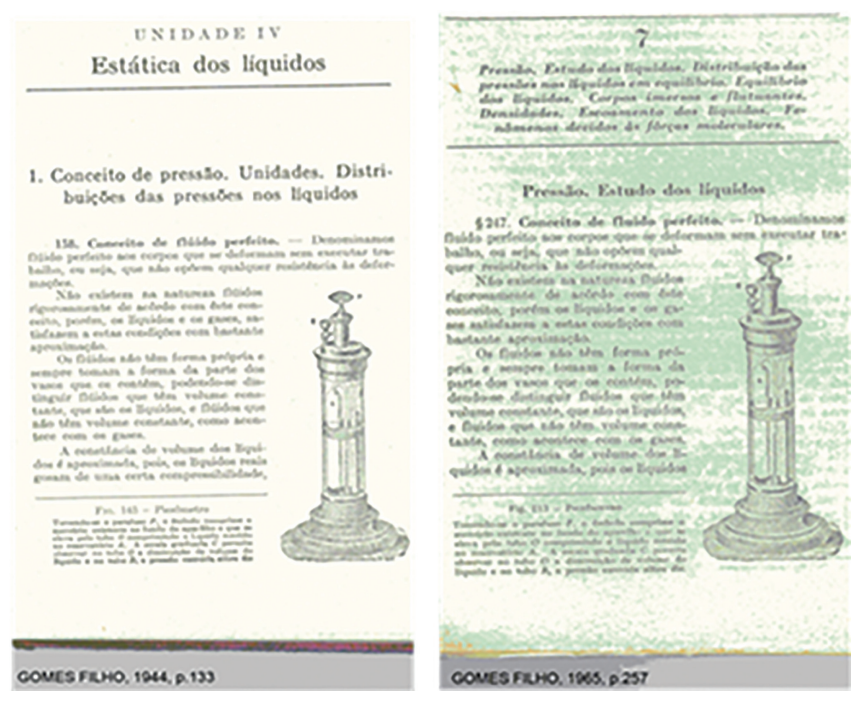

Figura 11: Trechos de livros de Gomes Filho.

Fonte: Gomes Filho [31] unidade iv] [37] p. 257].

por Gomes Filho: "De um modo geral, estes livros são adaptações dos anteriores com a transposição dos capítulos segundo a nova seriação..." 37 .

De fato, na Figura 11, são apresentados os mesmos textos em diferentes posições em livros de Gomes Fi- 
lho [31, 37], diferindo apenas nos títulos e subtítulos, sendo que as duas obras estão em acordo com as respectivas portarias vigentes.

Sobre os conteúdos a serem desenvolvidos, a introdução das teorias modernas da Física se destaca. Este tema é desenvolvido nos livros com apresentação de alguns elementos da Teoria Quântica como o átomo de Bohr e o modelo onda-partícula da luz [38, 39, também são observadas informações sobre a Relatividade como as transformações de Lorentz [38] ou, ainda, os postulados da Relatividade 39. Acerca da Física Nuclear, entretanto, aparece somente a menção à existência de pesquisas sobre a constituição do núcleo [39]. Esse conteúdo das teorias modernas da física ocupa nesses textos, somente, entre 5 a 10 páginas.

Os livros dessa época são todos em branco e preto, mantendo praticamente o formato e o número de páginas quase idênticos da década anterior. Merece destaque o livro de Salmeron [40] que apresenta fotos em branco e preto de aparelhos experimentais como bobina de Ruhmkorff, tubos de Raios-X, reostato de variação contínua, entre muitas outras. Um elemento adicional interessante nesse autor diz respeito às notas históricas apresentadas no final de cada capítulo, em que em cerca de meia página, relata-se a vida de algum cientista, bem como o significado de sua descoberta no contexto do desenvolvimento da física ou da evolução dos conceitos da física. Na mesma direção, a coleção de Teixeira Junior e Rizzo [39] apresenta na abertura de alguns capítulos uma pequena biografia do cientista significativo ao conteúdo a ser desenvolvido, acompanhada de sua "foto-desenho" (Figura 12).

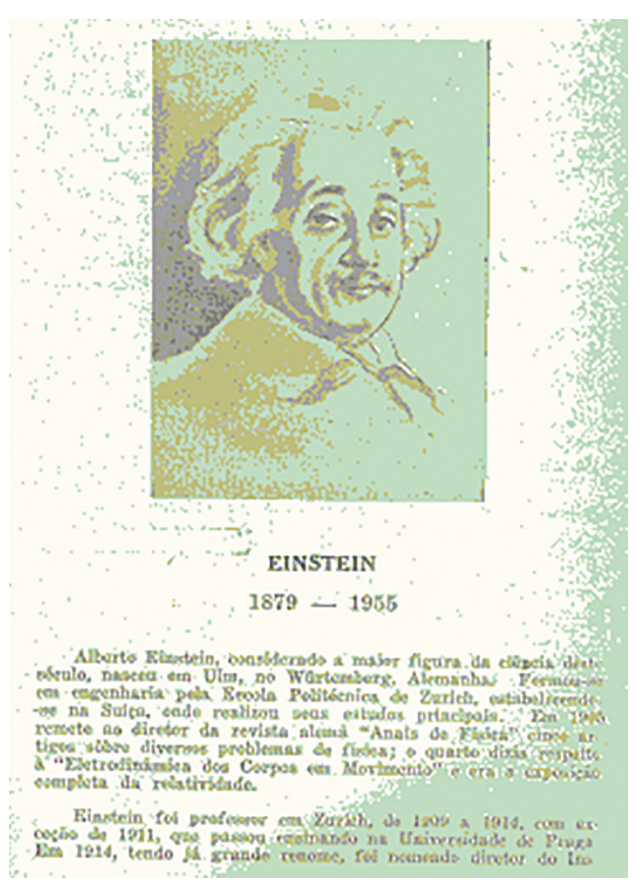

Figura 12: Trecho de livro de Teixeira Junior \& Rizzo. Fonte: Teixeira Junior \& Rizzo [39].
Na comparação dos livros das décadas de 1950 e 1960, com a década anterior, nota-se uma diminuição ainda maior do tratamento qualitativo e descritivo das máquinas e mecanismos (característico dos textos das décadas de 1930/1940) e o aumento no número de exercícios, problemas e testes de vestibulares. De fato, na obra de Gomes Filho, os livros da década de 1940 não apresentam listas de exercícios propostos, enquanto que seus textos do começo da década de 1950 trazem listas em finais de capítulos (cerca de 10 exercícios). Na década de 1960 essas atividades crescem quase três vezes (da ordem de 30 exercícios), incluindo alguns exercícios mais sofisticados e outros envolvendo desenvolvimento de solução. Em relação às atividades práticas, embora a Portaria ${ }^{\circ}$ 996/1951 preconize as experimentações, não as encontramos em nenhuma das coleções.

\section{Anos 1960 e 1970: as Duas Tendências na Literatura do Ensino da Física}

Após a promulgação da $1^{\mathrm{a}} \mathrm{LDB} / 1961$, foi facultada às escolas, a escolha de conteúdos das matérias escolares, libertando os programas curriculares do rigor no cumprimento de planos de ensino específicos. Essa legislação surge no bojo do convênio MEC/USAID, definindo as diretrizes básicas da educação, bem como a sua implantação, com mudança radical na educação brasileira. $\mathrm{Na}$ área de Física ${ }^{8}$ foi traduzido e distribuído o projeto americano Physical Science Study Committee (PSSC) (Figura 13) com tiragem de 240.000 exemplares na

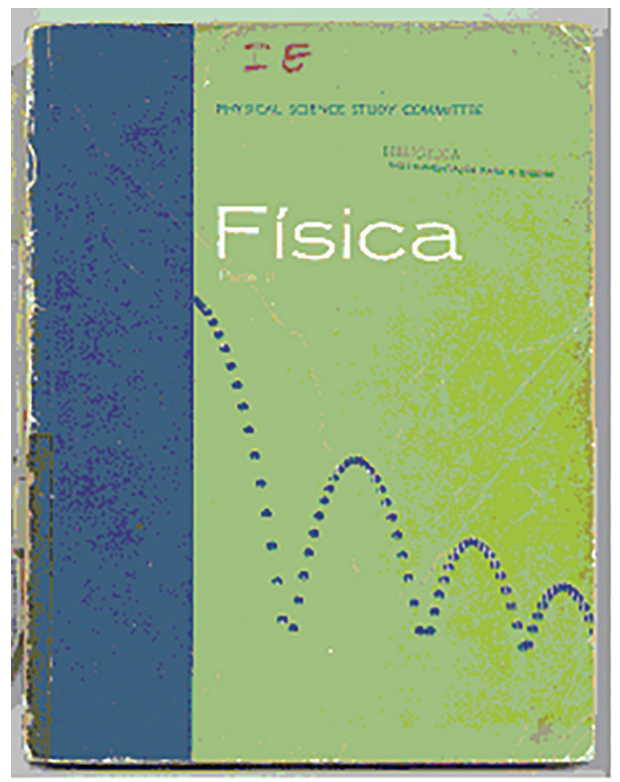

Figura 13: Capa de livro do projeto PSSC. Fonte: PSSC [41].

8 O PSSC, que em conjunto com obras similares de Biologia, Química, Matemática e Geociências passaram a ser adotados na década de 1960 


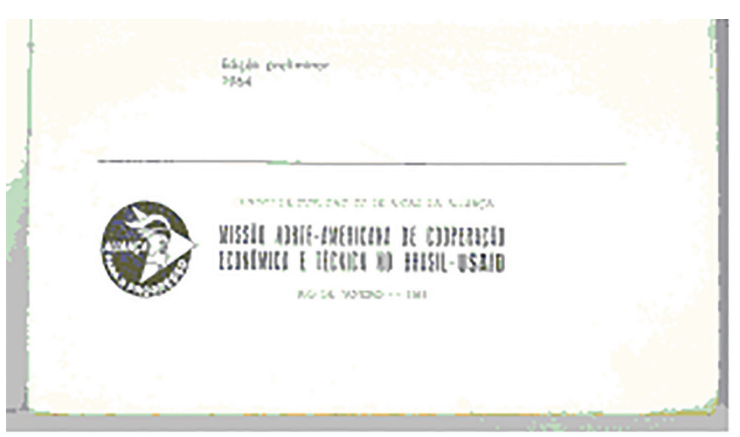

Figura 14: Trecho do verso da capa do PSSC. Fonte: PSSC [41].

\begin{abstract}
NOTA PARA ESTA EDIÇĀO:
Esta publicosỏo é uma tradução do obro "Physics" publicado $\mathrm{cm}$ ingles peto Physical Science Study publicodo $\mathrm{cm}$ ingles peto Physical seience Sicd Committer, em 1960. A presente edreo for publicada cooperotivamente pela Missōo Narte-Americons do Cooperoçäo Economica a Téenica no Brosil USAID - om prol da Alionko para o Progresso pela Editòra Universidodo de Brasilio, como parte do progromo do IBECC (Săo Poulo) desenvióvido som auxilio dos Fundacốes Ford e Rockefeller.
\end{abstract}

Figura 15: Trecho do verso da capa do PSSC. Fonte: PSSC 41].

edição preliminar de 1964. No verso da capa desta edição encontramos o logotipo da "Aliança para o Progresso" (Figura 14) e a nota mostrada na Figura 15 Estas informações desapareceram nas publicações posteriores, da década de 1970. Este projeto, concebido para as escolas americanas, visava: "atender as exigências de mudanças qualitativas e quantitativas da época pósSputnik, quando os grandes projetos para o ensino secundário foram implantados nos USA e na Europa, assim como em muitos outros países, e chegaram ao Brasil para revolucionar e modernizar o ensino da Física escolar, novamente sem que se verificasse se a escola brasileira estaria adaptada aos cursos alienígenas" [42, p. 5].

Embora o PSSC tenha se mostrado inadequado à realidade educacional brasileira, pode-se afirmar que esse projeto foi, sem sombra de dúvidas, um marco na história do ensino de Física no Brasil, a partir do qual se inicia a pesquisa dessa área.

Na mesma época surge um outro título representativo para a história do livro didático de Física elaborado por professores universitários Blackwood et al. 43 . traduzido pelos professores José Leite Lopes e Jaime Tiom ${ }^{9}$

\footnotetext{
9 Durante a década de 1950, professores universitários, de várias áreas, entre as quais destacamos Biologia, Física e Matemática, foram convidados pelo MEC, a escrever LD para essas disciplinas do ensino secundário. O professor Oswaldo Frota Pessoa se responsabilizou pelo título "Biologia na escola secundária" e o professor Euclides Roxo escreveu "Matemática na escola secundária" Na Física os professores José Leite Lopes e Jaime Tiomno, da UDF, atual UFRJ, ao invés de proporem um novo título, optaram pela tradução do livro americano de título original High School Physics, de autoria de Oswald H. Blackwood, Wilmer B. Herron e William
}

em volume único, com mais de 700 páginas, editado pelo MEC. Essa tradução, intitulada "Física na escola secundária", apresenta enfoque inovador, especialmente em relação aos conteúdos que abordam elementos do cotidiano como explicitado a seguir:

A Física deve ser aprendida como assunto atraente para explicar o mundo em que vive o estudante - não deve ser ensinada como um complexo de fórmulas, definições abstratas e máquinas complicadas... Na presente tradução fez-se algumas modificações com o objetivo de melhor adaptar o texto ao nosso meio. Em particular, no capítulo 20, o parágrafo intitulado "Exploremos o nosso petróleo e conservemos os nossos minérios atômicos" foi reescrito, mantendo-se, entretanto, o espírito do texto original 43. prefácio dos tradutores].

Ao lado desse movimento, financiado pelo MEC, pretendendo difundir livros didáticos com maior aprofundamento teórico alicerçado por uma nova proposta pedagógica, notamos os "Cadernos MEC", publicados pela FENAME, como o texto de Física de Maia [4], professor do Instituto de Física da UFRJ, contendo somente problemas para serem resolvidos. Nesse mesmo enfoque encontramos obras no final dos anos 1950 e início dos anos 1960, promovidas por professores, em sua maioria, atuantes em pré-vestibulares. Gabriades [4], Sengberg [46] e Antunes [47, professores do Curso Anglo Latino de São Paulo, são exemplos dessas publicações. Nestes livros ocorre uma simplificação de conteúdos e uma proliferação de exercícios e problemas, visando claramente a preparação aos exames vestibulares.

Ainda, é possível observar nesse período, livros específicos para treinamento aos exames, como por exemplo: "Testes orientados de Física 1: Mecânica" (com exercícios e problemas para o $2^{\circ}$. Grau e vestibular), de Gonçalves et al. 48, ou ainda "900 Exercícios de Física e o método de resolvê-los: 400 questões e 465 testes (com solução no final do livro)", de Rodrigues e Silva 35. (Figura 16). Ainda, Gonçalves [49 apresenta, ao final do livro, uma sessão de "Questões de vestibulares", divididas por ano $(1957,1958, \ldots$ ) e por localização (Bahia, Pernambuco, Guanabara, São Paulo,... ), ocupando cerca de $20 \%$ do livro. Nessas obras há pouca ou nenhuma explicitação de conteúdo, primando, portanto pela finalidade de treinamento aos exames de ingresso ao ensino superior.

Nesse período já é possível observar uma verdadeira hegemonia de São Paulo em relação ao mercado editorial de livros escolares de Física. Na década de 1960 ocorre

C. Kell, cujos direitos para a língua portuguesa foram adquiridos pelo órgão ministerial, Instituto Nacional de Estudos Pedagógicos, INEP. Este livro encontra-se disponível na íntegra na Biblioteca Virtual Leite Lopes (http://www4.prossiga.br/Lopes/prodcien/ fisicanaescola/indice.htm). 


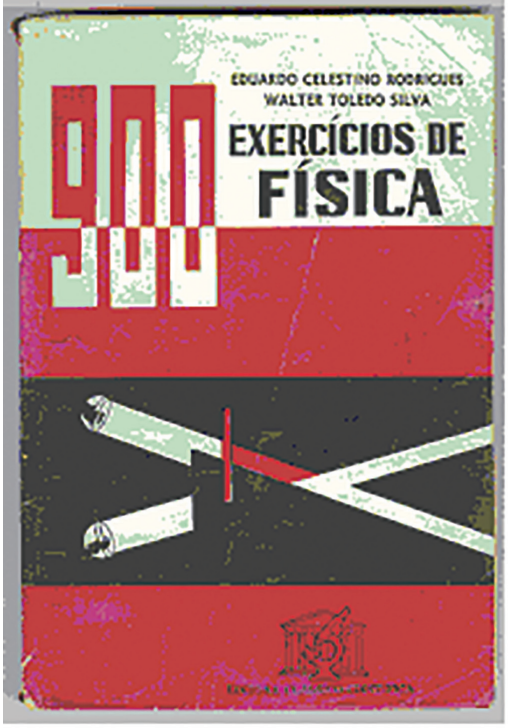

Figura 16: Capa de livro de Rodrigues \& Silva. Fonte: Rodrigues \& Silva [35].

uma expansão, dobrando o número de obras, passando de uma para duas dezenas de livros nacionais nesta área.

No início da década de 1970 vários projetos nacionais são desenvolvidos e testados: o PEF (Projeto de Ensino de Física); o FAI (Física Auto-Instrutivo) e o PBEF (Projeto Brasileiro de Ensino de Física). Todos esses projetos foram coordenados por professores de Universidades, com participação de professores de Física do ensino médio, almejando o desenvolvimento de um material didático em que o aluno trabalhasse praticamente sozinho, necessitando pouca ajuda do professor. Isso presumia um modelo de ensino aprendizagem centrado no aluno e não na relação aluno-professormaterial didático.

Esse fato pode ser vislumbrado nos seguintes excertos dos autores, no livro do aluno "O que é o PEF", do Instituto de Física da USP (Figura 17), em que são enfatizadas a formatação e a metodologia do referido Projeto de Ensino de Física:

O PEF destina-se aos alunos do curso médio, ou seja, alunos que, em geral, não mais estudarão física, vencido este nível. Julgamos assim importante proporcionar ao aluno um contato com assuntos que, com toda probabilidade, não mais serão abordados em sua formação subseqüente. Dessa maneira procuramos levar o aluno a conhecer o método científico através do estudo de alguns fenômenos.

... Elaboramos este curso para que você possa aprender física de um modo ativo. Isto significa que você vai realizar experiências, analisar e discutir e resolver problemas. Todas essas atividades são partes integrantes

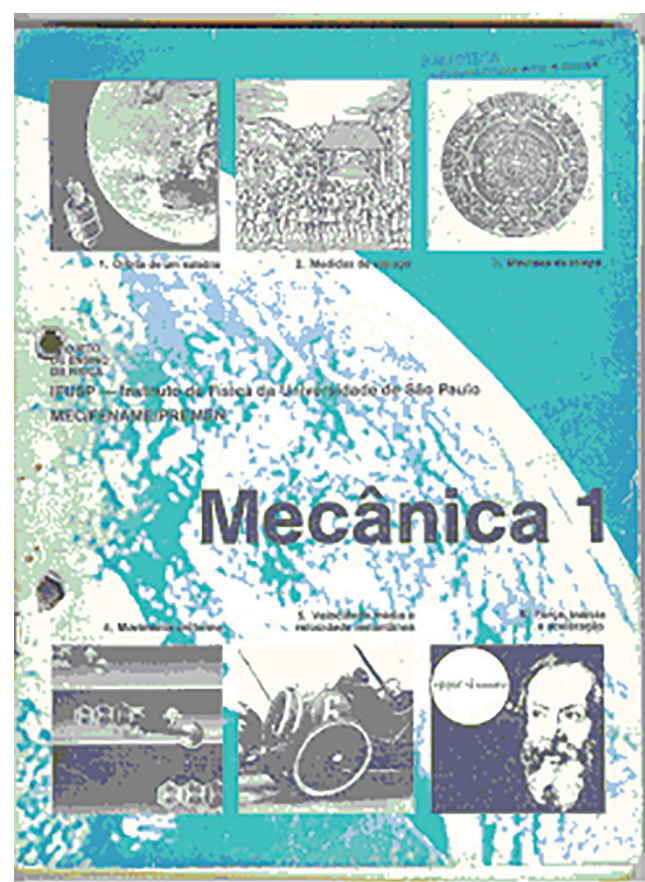

Figura 17: Capa de livro do projeto PEF. Fonte: IFUSP, PEF [50].

do texto. Não é possível seguir o curso sem realizar as atividades indicadas [50, prefácio].

O PEF não se preocupa em nenhum momento com o vestibular. Pode-se perceber que o seu objetivo vai à direção da formação cultural do aluno ("método científico") e, de forma compatível com essa visão, o desenvolvimento do curso é proposto através da realização de atividades experimentais. O texto auto-instrutivo, além do enfoque experimental e dinâmico, é escrito com uma linguagem dirigida ao estudante.

O FAI (Figura 18), elaborado pelo Grupo de Estudos em Tecnologia de Ensino de Física - GETEF, do Instituto de Física da USP, também é auto-instrutivo, apresentando, porém, natureza bem diferente do PEF. Na proposta do Projeto FAI, a sequência dos temas da física segue de certa forma, a sequência dos livros didáticos convencionais da época, enquanto que o desenvolvimento do livro segue a técnica da "instrução programada", como revela o seguinte excerto dirigido ao estudante:

... este volume é constituído de textos programados, cujo conteúdo foi cuidadosamente analisado e apresentado em pequenos passos (itens). Em cada passo é fornecida certa informação e, logo em seguida, uma ou mais questões são apresentadas. Você deverá ler atentamente e escrever a resposta à questão formulada em espaço próprio ou desenvolver à parte. Tendo respondido, deverá verificar se sua resposta corresponde a um acerto, comparando-a com aquela correta 


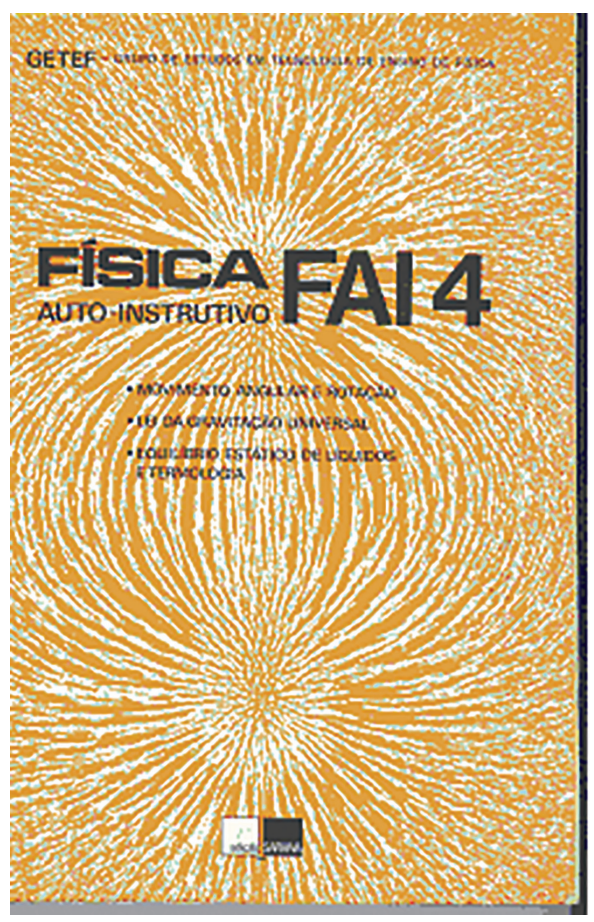

Figura 18: Capa de livro do projeto FAI.

Fonte: GETEF, FAI [51].

apresentada logo a seguir. Suas respostas servem de informação aos passos seguintes [51, prefácio].

Outros docentes universitários também fazem suas propostas de ensino de Física, incorporando algumas características inovadoras introduzidas pelo PSSC, tais como a importância conceitual, a presença de atividades experimentais para estudantes e as leituras complementares. Entre esses autores, citamos Alvarenga \& Máximo [52] (Figura 19), professores do Departamento de Física da UFMG, cuja proposta de ensino, para muitos professores do ensino médio, se adapta melhor às condições de ensino vigentes $[53$.

Outro autor que deve ser destacado é Lucie [54, professor do Departamento de Física da PUC do Rio de Janeiro, que apresenta o desenvolvimento do conteúdo através de diálogos entre Martins e ele, com ilustração de Henfil (Figura 20).

Ao lado destes projetos e propostas de ensino despontam grupos de autores, vários deles em colaboração duradoura como Ferraro et al. [55] e Pauli et al. [56]. Com exceção de Gonçalves [57], publicado no Rio de Janeiro e Alvarenga \& Máximo [52], editado, por uma única década, em Belo Horizonte, os demais livros pesquisados foram produzidos em São Paulo. Embora entre os autores ou grupo de autores da década de 1970, encontram-se profissionais formados em Física, sobretudo no IFUSP, onde o projeto PSSC estava presente na formação acadêmica, as suas obras são bastante instrumentais na resolução de exercícios e problemas, com pouco conteúdo conceitual, objetivando prioritariamente

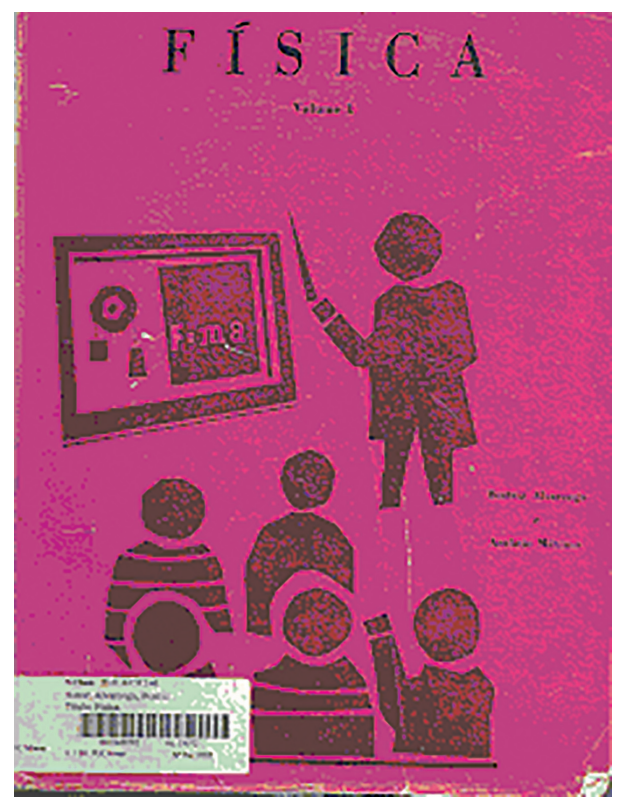

Figura 19: Capa de livro de Beatriz Alvarenga \& Antônio Máximo.

Fonte: Alvarenga \& Máximo [52].

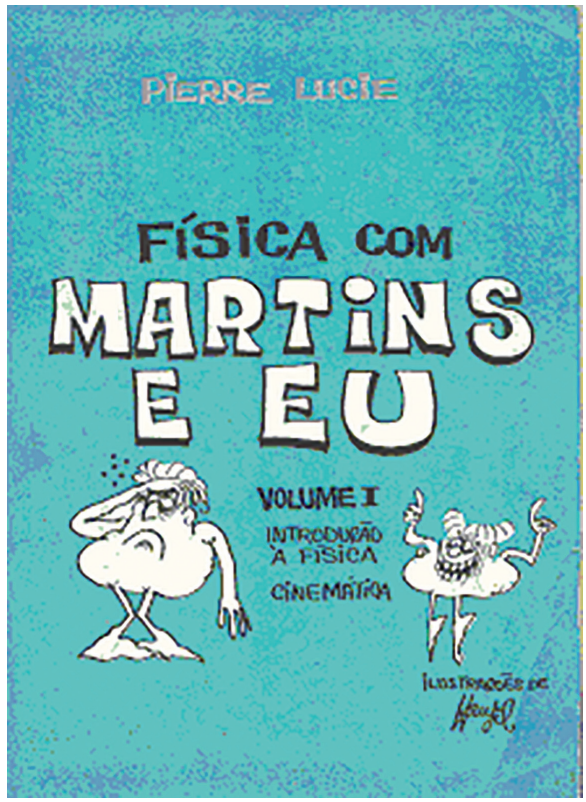

Figura 20: Capa de livro de Pierre Lucie.

Fonte: Lucie [54].

o treino em questões de vestibulares. Entre esses autores encontram-se Antunes [58, Ueno \& Yamamoto [59, Santos \& Righetto [60], Ferraro et al. [55], Merino 61], Lenz \& Moretto 62, Omote 63.

Em relação à literatura escolar de Física, nas décadas de 1960 e 1970, pudemos observar duas tendências bastante nítidas. De um lado estão aquelas produções que acompanham a tendência das obras de 1940/1950 que começam a privilegiar o aspecto quantitativo através de resolução de exercícios, problemas e testes 
de vestibulares, substituindo o tratamento qualitativo e descritivo das máquinas e mecanismos das décadas anteriores, em que o material didático se resume no livro para o aluno. De outro lado, aparecem os Projetos, com ênfase na compreensão conceitual e estrutural da Física, utilizando em sua metodologia de ensino, além do livro para o aluno, equipamentos experimentais e filmes, além do guia do professor.

Ao considerarmos as expectativas do ensino de Ciências desse período, compreendemos que, embora os Projetos de ensino tenham sido menos difundidos e mais rapidamente abandonados, os seus propósitos se adequavam melhor aos requisitos da Legislação vigente. De fato, o parecer $n^{\circ}$ 853/1971 que fixa o núcleo comum para os currículos do ensino de $1^{\circ}$ e $2^{\circ}$ graus, e a doutrina do currículo na Lei $\mathrm{n}^{\circ} 5692$, estabelecem que:

No início da escolarização, as Ciências (p.ex.) só podem ser tratadas em termos de atividades, isto é, como vivência de situações e exercícios de manipulação para explorar a curiosidade, que é a pedra de toque do método científico. Sempre que oportuno essas experiências já podem ser objeto de uma incipiente sistematização partida mais do aluno que do professor, embora sob a direção estimulante deste último. À medida que se esboçam certos setores ainda não claramente individualizados e tais sistematizações se tornam mais freqüentes, pelo amadurecimento natural do educando, já temos a área de estudo (Ciências Exatas e Biológicas, p.ex.); e nessa progressão se chegará à predominância do sistemático sobre o ocasional, com visão cada vez mais nítida de cada subárea (Matemática, Física, Química, Biologia, p.ex.) ou disciplina [64, prefácio].

Portanto, apesar da legislação vigente à época, consubstanciada na profissionalização compulsória, preconizar um trânsito contínuo entre atividades, áreas de estudo e disciplinas, o ensino do segundo grau não parece ter encontrado forte eco na literatura do ensino de Física dessa década.

\section{Algumas Considerações}

Um pouco da história da disciplina Física, da educação básica, pode ser desvelado através de elementos presentes nos livros de didáticos identificados ao longo de 30 anos, aproximadamente de 1940 a 1970. Foi possível identificar que a partir da década de 1940 o mercado editorial de livros didáticos se concentra em São Paulo, passando a ser exclusivamente paulista desde a década de 1970. Esse fato pode ser compreendido pelo tamanho deste mercado consumidor de livros didáticos, pela disponibilidade de mão de obra qualificada e pela referência deste Estado no âmbito da educação brasileira. No cenário educacional, entre 1940 e 1960, a cidade do Rio de Janeiro também ocupa posição relevante, sendo o Colégio Pedro II responsável pela elaboração dos programas obrigatórios das disciplinas escolares de todas as reformas ocorridas neste período. Apesar da concomitância de oferta, entre as décadas de 1940 e 1960, do clássico e do científico como modalidades de ensino obrigatório para ingresso às faculdades, o ensino de física dos livros didáticos é quase que totalmente dirigido para o científico, com cerca de 9 aulas/semana, em contraposição às 6 aulas/semana destinadas ao clássico. Este número de horas aulas da física mostra a importância desta disciplina no cenário nacional da época centrada no desenvolvimento do pensamento científico e formação tecnológica. A partir da lei $\mathrm{n}^{\circ} 5692 / 1971$, com a obrigatoriedade da formação profissional, a disciplina Física perde espaço, sendo incorporada na disciplina Ciências Físicas e Biológicas, com um número de aulas/semanais definido em função das áreas de profissionalização de cada escola. A maioria das escolas públicas passa a adotar, em média, 2 aulas/semana, distribuição que perdura até os dias atuais, sobretudo nas escolas públicas.

A maioria dos autores de LD de Física também é de São Paulo, sendo professores de escolas públicas nos primeiros períodos (1940-1950) e professores de cursos preparatórios para o vestibular nas décadas seguintes (1960-1970), muitos deles com livros editados por até 3 (três) décadas. Atualmente há autores cujos livros foram lançados na década de 1970, o que significa uma permanência no mercado editorial por mais de 50 anos.

Embora nesse período tenha ocorrido três reformas educacionais, diferenciando-se de uma proposição que valoriza o pensamento cientifico teórico (década de 1940), para a outra que reformula os temas da física baseando-se nas áreas da ciência física e acrescentando em sua formulação a importância do caráter experimental (década de 1950) e em seguida para uma terceira objetivando a formação tecnológica e profissional (décadas de 1960/1970), a proposta de ensino de Física concretizada em LD de cada autor mudou muito pouco, resumindo-se em pequenos acréscimos ou troca de posições no interior do livro, visando a sua adequação a cada nova demanda legal.

Os temas da Física abordados nos livros são determinados pelo programa obrigatório, porém os enfoques e abordagem de desenvolvimento são diferentes, identificando fundamentalmente duas visões de ensino de física no período de 1940-1960: de um lado a compreensão de que o ensino de física é mais um conjunto de informações a serem memorizados pelos alunos com apresentações de definições e relações de grandezas físicas e enunciações de leis e suas simples aplicações numéricas; de outro, que a física além das definições, relações e leis se complementam com suas conceituações e seu caráter experimental e/ou cultural. Existem, ainda, autores que se localizam entre as duas visões, revelando diferentes propostas de ensino de física em seus livros.

A chegada do PSSC no Brasil representa um marco para o ensino da Física, levando às reflexões que 
resultaram em projetos de ensino no início da década de 1970, todos com sede em São Paulo. O que muda nestes projetos são as formas no desenvolvimento dos conteúdos: um incorpora uma visão mais cultural, com a Física bastante contextualizada e o caráter experimental bastante explorado. Na outra vertente está o projeto com conteúdos bastante teóricos e conceituais, semelhante ao desenvolvimento dos conteúdos propostos em universidades de formação de físicos ou professores de física. Concomitantemente, propostas de ensino são apresentadas em LD divulgados por editoras comerciais e elaborados por dois tipos de autores: aqueles ligados aos cursos pré-vestibulares que preservam uma visão mais simplificadora e fragmentada e aqueles que derivam dos projetos de ensino ou de propostas anteriores mais conceituais e contextualizadas. Pode-se dizer que a década de 1970 foi um dos períodos mais ricos em termos de proposições em ensino de física, com a presença de diferentes visões de física e de ensino.

O contexto da política educacional do início da década de 1970, bem como a não obrigatoriedade de um programa de conteúdos favoreceram o aparecimento de uma maior variedade de proposições para o desenvolvimento da disciplina Física, aspecto bastante positivo. Uma continuidade seria pesquisar a natureza das propostas de ensino de física das fases posteriores, períodos em que não existe nenhuma orientação programática em nível nacional sobre o ensino de física, mas novas perspectivas da educação como pedagogia crítica, construtivismo, concepções espontâneas, entre outras e da física como a compreensão da ciência como construção humana, sua história e seus modelos explicativos, que se iniciam na década de 1970.

\section{Referências}

[1] E.F. Goodson, Currículo: teoria e história (Vozes, Petrópolis, 1995).

[2] A. Choppin, Educação e Pesquisa 30, 549 (2004).

[3] M.I. Martins e Y. Hosoume, em: Simpósio Internacional Livro didático: Educação e História (São Paulo, 2007), p. 1106.

[4] M.N.A. Queiroz, O ensino de Física no Brasil nas décadas de 1960 e 1970: legislação, currículo e material didático. Tese de Doutorado, Universidade de São Paulo, São Paulo (2016).

[5] S.B. Schirmer e I.P.S. Sauerwein, Investigações em Ensino de Ciências 22, 23 (2017).

[6] R.B. Nicioli Junior, O Conteúdo de cinemática nos livros didáticos de 1810 a 1930. Dissertação de Mestrado, Universidade de São Paulo, São Paulo (2007).

[7] L.A. Tavares, A imagem impressa e ciência: ilustrações em livros didáticos de física (séculos XIX e XX). Dissertação de Mestrado, Pontifícia Universidade Católica de São Paulo, São Paulo (2005).

[8] V.R. Martins, $O$ ensino de física moderna nos livros didáticos do início do século XX. Dissertação de Mestrado, Universidade de São Paulo, São Paulo (2014).
[9] BRASIL. Lei $\mathrm{n}^{\circ}$ 4.024, 20 de dezembro de 1961. Brasília, 1978. Disponível em: http://www.planalto.gov.br/ccivil -03/leis/14024.htm.

[10] BRASIL. Lei n 5.692, 11 agosto de 1971. Brasília, 1971. Disponível em: https://www.camara.leg.br/proposicoe sWeb/prop_mostrarintegra;jsessionid=F8342BB4536 FBA13C8A2FC6081001C83.proposicoesWebExtern $\mathrm{o} 2$ ? codteor $=713997 \&$ filename $=$ LegislacaoCitada+-PL $+6416 / 2009$

[11] BRASIL. Decreto n ${ }^{\circ}$ 4.244, 09 de abril de 1942. Brasília, 1942. Disponível em: https://www2.camara.leg.br/legin /fed/declei/1940-1949/decreto-lei-4244-9-abril-1942-41 4155-publicacaooriginal-1-pe.html

[12] O.O. Romanelli, História da Educação no Brasil: 1930/1973 (Vozes, Petrópolis, 1985).

[13] BRASIL. Portaria n 170, 13 de março de 1943. Brasília, 1943.

[14] BRASIL. Portaria n 966, 2 de outubro de 1951. Brasília, 1951.

[15] A. Vechia e K.M. Lorenz, Programa de ensino da escola secundária brasileira: 1850-1951 (Editora do Autor, Curitiba, 1998).

[16] R. Nardi, Investigação em Ensino de Ciências 10, 63 (2005).

[17] M. Krasilchic, São Paulo em Perspectiva 14, 85 (2000).

[18] M.N.A. Queiroz e Y. Hosoume, Ensaio: Pesquisa e Educação em Ciências 20, e9723 (2018).

[19] J Kleiber, Compêndio de Física (Globo, Porto Alegre, 1933).

[20] O.B. Lourenço, Tratado elementar de Física experimental (Nacional, Rio de Janeiro, 1938).

[21] F.R. Nobre, Tratado de Física elementar (Ailland \& Lelo, Porto, 1934).

[22] A. Magalhães, Elementos de Física (Globo, Porto Alegre, 1934).

[23] U. Pereira, Curso de Física (Saraiva, São Paulo, 1944).

[24] F.A. Gomes Filho, Física para a terceira série do curso colegial (Nacional, São Paulo, 1944).

[25] I.M. Marciano, Física: ciclo colegial: $2^{\mathrm{a}}$ série do curso científico (Francisco Alves, Rio de Janeiro, 1946).

[26] A. Freitas, Física: $1^{\circ}$ livro: ciclo colegial (Melhoramentos, São Paulo, 1948)

[27] F.A. Gomes Filho, Física para o segundo ano do curso colegial (Nacional, São Paulo, 1955).

[28] A. Freitas, Física: $1^{\circ}$ livro: ciclo colegial (Melhoramentos, São Paulo, 1953).

[29] E. Rodrigues Celestino e R.R. Pieroni, Física: $1^{\mathrm{a}}$ parte (Clássico-científico, São Paulo, 1957).

[30] A. Freitas, Curso de Física: $3^{\mathrm{a}}$ Série: iniciação ao estudo dos fenômenos físicos (Melhoramentos, São Paulo, 1946).

[31] F.A. Gomes Filho, Física para o primeiro ano do curso colegial (Nacional, São Paulo, 1944).

[32] H.U. Nabholtz, Física: primeiro volume (Editora do Brasil, São Paulo, 1948).

[33] A. Freitas, Física: $3^{\circ}$ Livro Ciclo Colegial (Melhoramentos, São Paulo, 1949).

[34] E.C. Rodrigues e R.R. Pieroni, Física $2^{\mathrm{a}}$ Parte (ClássicoCientífica, São Paulo, [194-]). 
[35] E.C. Rodrigues e W.T. Silva, 900 exercícios de Física e o método de resolvê-los (Clássico-Científica, São Paulo, [196-]).

[36] BRASIL. Portaria $\mathrm{n}^{\circ}$ 1045, 14 de dezembro de 1951 Brasília, 1951.

[37] F.A. Gomes Filho, Física para o primeiro ano do curso colegial (Nacional, São Paulo, 1965).

[38] F.A. Gomes Filho, Física para o $3^{\circ}$ ano do curso colegial (Nacional, São Paulo, 1965).

[39] A.S. Teixeira Junior e M. Rizzo, Física $3^{\mathrm{a}}$ série (Editora do Brasil, São Paulo, 1958)

[40] R.A. Salmeron, Introdução à eletricidade e ao magnetismo ([s.n.], São Paulo, 1958).

[41] PHYSICAL SCIENCE STUDY COMMITTEE, Física (Universidade de Brasília, Brasília, 1964).

[42] S.S. Barros, em: VIII EPEF - Encontro de Pesquisa em Ensino de Física (Águas de Lindóia, 2002).

[43] O.H. Blackwood, W.B. Herron e W.C. Kelly, Fúsica na Escola Secundária (MEC, Brasília, 1961).

[44] L.P.M. Maia, Física 1: ótica geométrica e termologia (MEC/FENAME, Brasília, 1969).

[45] E. Gabriades, Fúsica: estática dos líquidos, estática dos gases, termometria (Massao Ohno, São Paulo, 1960).

[46] G. Sengerb, Eletricidade: tomo 1 eletrodinâmica (Nobel, São Paulo, 1962).

[47] A.A.N. Antunes e L. Fragoso, Eletrodinâmica para o vestibular ([s.n.], São Paulo 1967).

[48] D. Gonçalves, A.C. Bazin, G.S. Oliveira, L.A. Guimarães, L.A. Machado e T.G. Justo, Testes orientados de Física: Mecânica (Ao Livro Técnico, Rio de Janeiro, 1978).

[49] D. Gonçalves, Física do científico e do vestibular (Ao Livro Técnico, Rio de Janeiro, 1966).

[50] Instituto de Física da Universidade de São Paulo, Projeto de Ensino de Física: Mecânica 1 (MEC/FENAME, São Paulo, 1974).

[51] Grupo de Estudos em Tecnologia de Ensino de Física, Física auto-instrutiva: FAI4 (Saraiva, São Paulo, 1974).

[52] B.G. Alvarenga e A. Máximo, Física: v.1 (Bernardo Álvares, Belo Horizonte, 1970).

[53] A.M.P. Carvalho, Revista Brasileira de Física 4, 531 (1974).

[54] P. Lucie, Física com Martins e eu (Raval Artes Gráficas, Rio de Janeiro, 1969).

[55] N.G. Ferraro, P.A.T. Soares, J.I.C. Santos e F. Ramalho Junior, Fundamentos da Física: 1: mecânica (Moderna, São Paulo, 1976).

[56] R.U. Pauli, F.S. Marorama, H.P. Heilmann e C.A. Chohfi, Física 1: Mecânica (EPU, São Paulo, 1978).

[57] D. Gonçalves, Física: vol 2: termologia (Ao Livro Técnico, Rio de Janeiro, 1978).

[58] A.A.N. Antunes, Física na Escola Nova (Moderna, São Paulo, 1972)

[59] P.T. Ueno e I. Yamamoto, Estudos de Física: Mecânica (Moderna, São Paulo, 1977).

[60] U.P. Santos e L. Righetto, Física: $2^{\circ}$ grau: $1^{\text {a }}$ série (Atual, São Paulo, 1977).

[61] D. Merino, Física 1: série compacta (Ática, São Paulo, 1979).
[62] U. Lenz e V.P. Moretto, Física em módulos de ensino (Ática, São Paulo, 1979).

[63] N. Omote, Física: mecânica, termologia, óptica, eletricidade, eletromagnetismo e ondas (Moderna, São Paulo, 1979).

[64] Brasil. Parecer n 853, 12 de novembro de 1971. Brasília, 1971. 